\title{
Quality Assurance Culture in Niger Delta University: A Necessity for Enhancing Standards and National Transformation
}

\author{
Dr Allen A. Agih \\ Dept of Educational Foundations \\ Faculty of Education, Niger Delta University \\ Wilberforce Island, Bayelsa State, Nigeria \\ Email: agihallen@yahoo.com
}

\section{Doi:10.5901/jesr.2013.v3n3p201}

\section{Abstract}

The study was a descriptive survey which sought to find out how well the operators of Niger Delta University understand and utilize some of the quality assurance culture indices in the management of the institution. A sample of 660, which represented $50 \%$ of the entire population of 1333 (760 academic and 573 non-academic staff) was obtained through the Simple Random Sampling Technique. Three research questions were developed to guide the study, and the instrument for data collection was a questionnaire titled, "Perception of Quality Assurance Culture Questionnaire" (PQACQ).The reliability coefficient was established at $0.74 \%$. Findings revealed that operators of the system do not possess most of the quality assurance cultural indices required to enhance quality and standards in the University. This equally made it difficult for them to utilize the quality assurance culture required in the management of the institution. It was therefore recommended that seminars/ workshops be organized to instill in management staff some of the cultural values of quality assurance, if the system must achieve the desired goal of quality improvement. Also, the study recommended the inculcation and effective assessment of the affective characteristics of pupils/ students while still in school to prepare them for the world of work and others.

\section{Introduction}

Quality assurance is meeting or conforming to general accepted standards as defined by quality assurance bodies or appropriate academic and professional committees. According to Whitely (2001), quality assurance in education has become an all-embracing concept that includes all policies, processes and actions through which the quality of education provided is developed and maintained. For higher education institutions, this requires them to demonstrate responsible actions in their professional practices, be accountable for public funds received and demonstrate the results they have achieved with the available resources.

Accordingly, the need to assess quality in educational provision is now generally accepted as one of the tools of educational reforms. There are two widely used systems of quality assurance in higher education. The first is the system decertification of students by a renowned scholar reputation of the scholar in the field. The value of the credentials awarded, are assured by the reputation of the scholar as well as his place in the genealogical succession of established scholarship in the field of study. This brand of quality assurance has evolved into one of internal and external peer review of students' performance and advancement of scholarship within the academia.

The other system is the accreditation of institutional or professional programmes. The essence of accreditation system is that of meeting input standards in such areas as curriculum; library facilities; staff qualifications; students' entry qualifications; duration of study etc. It should be noted that the two systems are mutually inclusive. The current tendency is for the two approaches to be grafted into one another (Miller, 2002).

Similarly, Enaohwo (2008) observed that quality is multifaceted and multidimensional and is liable to different interpretations, depending on the area of focus, and that the concept of quality is rather abstract. However, according to him, it can be assessed through the following:

i. Conforming with requirements;

ii. Meeting the customer requirements;

iii. Fitness for intended purpose, and fitness of purpose;

iv. Providing an efficient and effective service to customers;

V. Preventing things from going wrong and getting everything right first time, every time; 
vi. Involving everything concerned from conception to after sales services;

vii. Involves the continuous enhancement and improvement of services.

Furthermore, Coombs (1995) defined quality education as judged in terms of student learning achievements, or the relevance of what is taught and learned, and how well this fits the present and future needs of the learners. However, various stakeholders do measure quality education from different perspectives. Students may be concerned about quality of teaching-learning process, while teachers do measure the internal functioning and efficiency of outputs and processes, while employers and society focus on the quality of output or its external level efficiency/effectiveness. Thus, the definition of quality in education must hinge on a number of variables that are of interest to those concerned. Quality, therefore, is a relative concept, depending on the areas of interest, attention and focus.

Furthermore, Enaohwo (2008) argued that quality education can be classified as (a) status variables and (b) process variables. The quality of school facilities like textbooks, libraries, classrooms and furniture, class size and general school environment; instruction time, homework frequency, and pupil-characteristics, their innate ability, readiness and willingness to learn, students' health and nutrition status and motivation.

In terms of process variables, or the mechanism for translating the status variable into desirable outcomes are, (a) methods of teaching, supervision and management of human and physical resources, space utility, time utility, pupils' activities; process accountability and service delivery. These are more relevant for effective service deliver in the education sector. Finally, quality relevance of curriculum and, above all, adequate funding and accountability. In this regard, the role of government as a reformer, with strong, robust long-term sustainable visionary policy can be a vital ingredient for quality education.

Quality assurance therefore both as an institutional or mechanism holds the key to the attainment of national goals or priorities through the sustainability of standards within the entire educational system of a country. This explains why the Federal Government of Nigeria established appropriate quality assurance agencies such as the National Universities Commission (NUC), National Commission for Colleges of Education (NCCE), National Board for Technical Education (NBTE) and others to enforce minimum standards at the various levels of tertiary education in Nigeria.

Quality assurance from the foregoing connotes a measure of achieving desirable level of accountability among different components of the educational system. However, there are two distinct approaches to quality assurance namely internal and external control measures. The former refers to in-built self-regulating measures in an organization for the attainment of efficiency or standards while, the latter consists of the statutory roles by designated quality assurance agencies such as NCCE, Teachers' Registration Council of Nigeria (TRCN) and others.

\section{The Problem}

In the Nigerian University system, apart from the National Universities Commission (NUC), Joint Admission and Matriculation Board (JAMB) and other bodies that are responsible for setting and maintaining minimum benchmark and standards, the individual universities equally have some internal mechanisms for ensuring quality assurance in the system. Some of these internal mechanisms are the Committee System, Mock Accreditation, Post University Matriculation Examination and others.

However, what is apparent from the background discussion of the concept does not pay sufficient attention to the "how" of the concept, which is concerned with the operators (people), their values, ideas, beliefs, which maybe referred to as the cultural indices of quality assurance. The subject of quality assurance in Nigerian Universities can not be meaningfully addressed outside the context of the cultural dimension of the concept. Emphasis has always been on the processes, the methods and tools with no corresponding attention given to the virtues, values, beliefs and dispositions of the people who operate the system and manage the processes. All these and others constitute culture, which is very important for the individual and the progress an organization will make.

Culture generally relates to how a people behave, their beliefs and how they do their things. The culture of an organization will therefore mean how staff relates with themselves and their behaviour towards the work process; how the organization treats the staff and how they expect to treat one another. Usually, these shared values and beliefs are put into expression through the leadership, and shared by the members of the organization. Therefore, the prevailing culture in an organization will depend on how the leader expresses those things he holds as beliefs and values. Accordingly, some of the shared values and beliefs of quality assurance culture as reported by Sashkin and Kiser (1993) are honesty, discipline, self-control, commitment, co-operation/team spirit, enthusiasm for work, general work ethics, conscientiousness and others. Drucker (1987) classified the cultural values of effective business management as motivation drive of the executive, self-mastery and a sense of social interaction in organization as displayed by the 
manager. Similarly, Agih and Jonah-Eteli (2011) have reiterated that a sense of patriotism, honesty, responsibility, discipline, spirit of oneness, positive character for the youths/adults alike, and the development of other matters of the heart are what the nation needs most to achieve sustainable transformation.

This study is therefore conducted to examine the perception of some academic and non-academic staff on how well the operators of the Niger Delta University understand and utilize some of the quality assurance cultural indices mentioned above in their administrative functions to achieve the goal of quality improvement in the university.

\section{Research Questions}

The following research questions were developed to direct the study:

1. What are some of the underlying cultural indices of quality assurance that operators of Niger Delta University need to possess?

2. To what extent are the quality assurance cultural indices being utilized in the management of the university?

3. How can the cultural values of quality assurance be improved upon and sustained by the operators in the management of the university?

\section{Methodology}

The study was a descriptive survey. Population of the study was 1333; drawn from the 760 academic staff and 573 nonacademic senior staff of the Niger Delta University (Academic Planning Office, 2011). A sample of 660, representing 50\% of the population was obtained using the Simple Random Sampling Technique. The questionnaire used was Perception of Quality Assurance Culture Questionnaire, "PQACQ". Mean ranking was used to analyze the data collected. Three research questions were developed to guide the study. The coefficient reliability index was established at 0.74 , which was found to be highly reliable at $0.05 \%$. The study recorded a $100 \%$ return rate, and so, data analyzed was based on the sample of the study.

\section{Results}

Research question one: What are some of the underlying cultural indices of quality assurance that operators of universities need to possess?

Results for research question one are presented in table 1 below.

Table 1: Mean Ranks of Cultural Indices of Quality Assurance in Ascending Order

\begin{tabular}{|c|l|l|l|}
\hline S/N & \multicolumn{1}{|c|}{ Evaluation Criteria } & & \\
\hline A. & Motivation & B. Self-Mastery & C. Social Skills \\
\hline 1. & Achievement drive & Self-control & Leadership \\
\hline 2. & Commitment & Trustworthy & Communication \\
\hline 3. & Dedication & Conscientiousness & Change catalyst \\
\hline 4. & Enthusiasm for work & Discipline & Conflict management \\
\hline 5. & Optimism & Innovativeness & Collaboration/ team spirit \\
\hline
\end{tabular}

The opinions of the participants on the motivational, self-mastery and social skills elements of the cultural parameters of quality assurance needed by university administrators are listed in ascending order in table 1 . The table result indicates that the primary value and belief of operators of the system that will enhance the quality assurance philosophy has to do with one having a sense of achievement drive. This is followed by commitment, dedication, enthusiasm and optimism in that order as regards the motivational indices. On self-mastery, participants identified self-control as primary followed by trustworthiness, conscientiousness, discipline and innovativeness. On the value of social skills, participants perceived leadership, communication, ability to effect change, conflict management skills and collaborative spirit as core cultural factors for management staff of the university to possess to enable them achieve quality assurance in the system.

Research question two: To what extent are the quality assurance cultural indices being utilized in the management of the university?

Results for research question two are presented in tables $2 a, b$ and $c$ and are equally presented in bar charts in 
the figures below.

Table 2 a.: Mean Ranks of Utilization of Cultural Indices of Quality Assurance by Operators (Motivation)

\begin{tabular}{|c|l|c|c|}
\hline S/N & \multicolumn{1}{|c|}{ Evaluation Criteria } & Mean Rank & Interpretation \\
\hline A. & Motivation & & \\
\hline 1. & Achievement drive & 1.92 & Low \\
\hline 2. & Commitment & 1.99 &,$"$, \\
\hline 3. & Dedication & 1.80 &,$"$, \\
\hline 4. & Enthusiasm for work & 2.01 &, \\
\hline 5. & Optimism & 1.98 & \\
\hline & Average Mean & 1.94 & \\
\hline
\end{tabular}

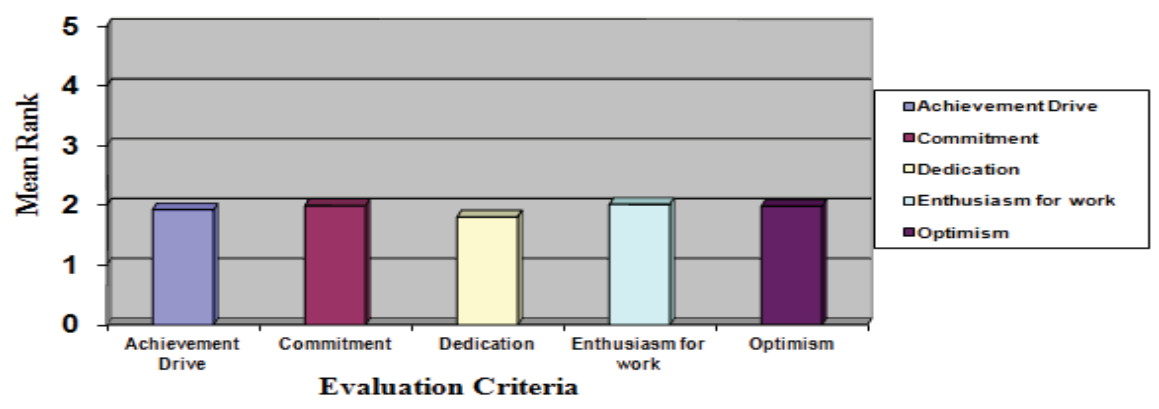

Fig. 1: Bar Chart of Cultural Indices (Motivation) of Quality Assurance.

The table analyses of the Mean ranking of the motivation elements as part of the cultural indices of quality assurance indicate that operators of the university system are poorly motivated. This is revealed from the average Mean of 1.94, and presented in fig. 1.

Table 2 b.: Mean Ranks of Utilization of Cultural Indices of Quality Assurance by Operators (Self-Mastery)

\begin{tabular}{|c|l|c|c|}
\hline S/N & \multicolumn{1}{|c|}{ Evaluation Criteria } & Mean Rank & Interpretation \\
\hline B. & Self-Mastery & & \\
\hline 1. & Self-control & 2.13 & Low \\
\hline 2. & Trustworthy & 1.99 &,$"$, \\
\hline 3. & Conscientiousness & 2.09 & ", \\
\hline 4. & Discipline & 1.72 &,$"$, \\
\hline 5. & Innovativeness & 2.11 & ", \\
\hline & Average Mean & 2.01 & \\
\hline
\end{tabular}

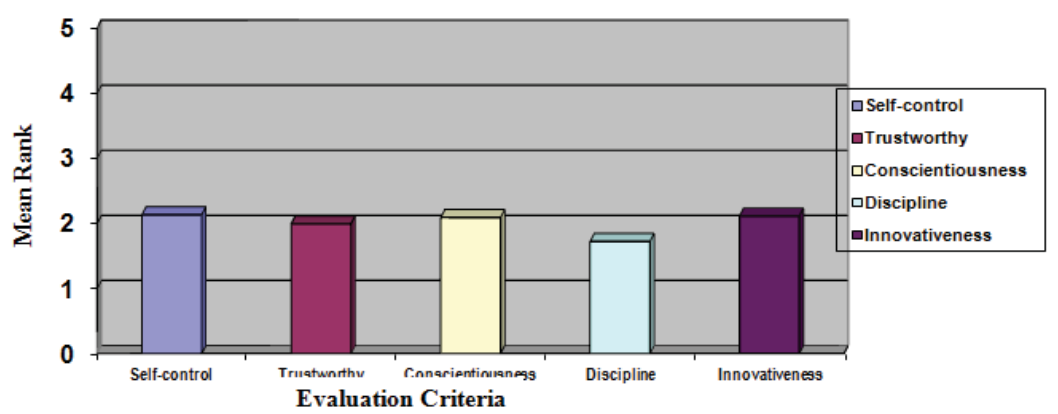

Fig 2: Bar Chart of Cultural Indices (Self-Mastery) of Quality Assurance. 
Analysis of self-mastery elements which constitute another aspect of the cultural indices of quality assurance also revealed poor utilization of this skill by the operators of the system. This is clearly shown from the average Mean value of 2.01. Figure 2 as presented also illustrate this.

Table 2 c.: Mean Ranks of Utilization of Cultural Indices of Quality Assurance by Operators (Social Skills)

\begin{tabular}{|c|l|c|c|}
\hline S/N & \multicolumn{1}{|c|}{ Evaluation Criteria } & Mean Rank & Interpretation \\
\hline C. & Social Skills & & \\
\hline 1. & Leadership & 2.15 & LoW \\
\hline 2. & Communication & 2.10 &,$"$, \\
\hline 3. & Change catalyst & 1.84 &,$"$, \\
\hline 4. & Conflict management & 2.12 &,$"$, \\
\hline 5. & Collaboration/ team spirit & 2.22 &, \\
\hline & Average Mean & $\mathbf{2 . 0 9}$ & \\
\hline
\end{tabular}

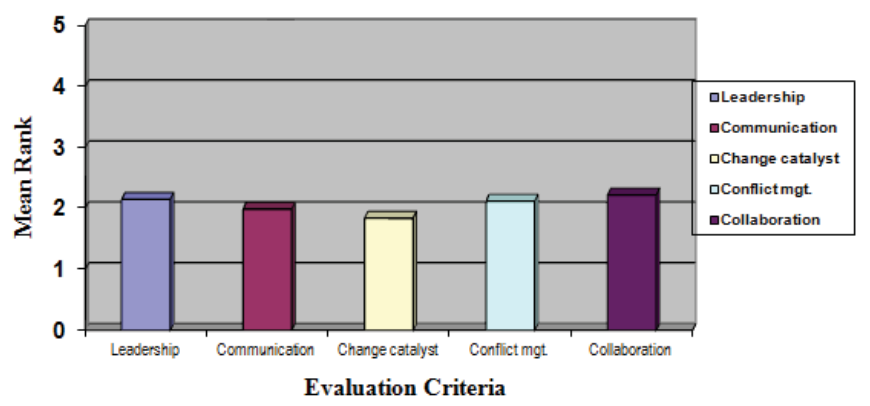

Fig. 3: Bar Chart of Cultural Indices (Social Skills) of Quality Assurance

The last cultural variable was on certain social skills as indicated in the table. Results show an average Mean of 2.09. This result also portrays poor understanding and utilization of this cultural index by the management staff of the university as equally shown in fig. 3.

Research question three: How can the cultural values of quality assurance be improved upon and sustained by the operators in the management of the university?

Results for research question three are presented below in table 3 and figure 4 below.

Table 3: Mean Rank Opinion on ways to improve the Utilization of Cultural Indices of Quality Assurance in the Management of Universities

\begin{tabular}{|c|l|c|c|}
\hline S/N & \multicolumn{1}{|c|}{ Evaluation Criteria } & Mean Rank & Interpretation \\
\hline 1. & Development of affective skills & 4.25 & High \\
\hline 2. & Effective assessment of affective domain of students while in school & 3.35 &,$"$ \\
\hline 3. & Inculcation of moral/social values by the family & 3.45 & $"$, \\
\hline 4. & Through seminars/ workshops & 3.34 &,$"$ \\
\hline 5. & Effort of religious groups & 3.12 & ", \\
\hline & Average Mean & 3.50 &, \\
\hline
\end{tabular}




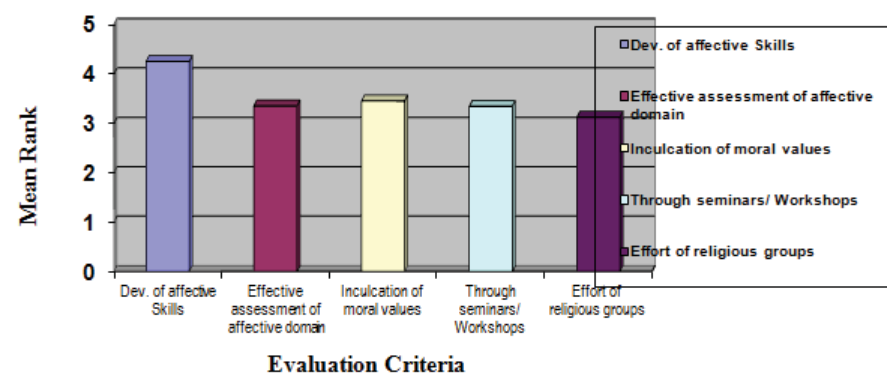

Fig. 4: Bar Chart of Respondents' Opinion on how to Improve the Utilization of Cultural Indices of Quality Assurance

The opinion of respondents on ways to improve the utilization of the cultural indices of quality assurance as shown in table 3 indicates the strong need for the operators of the system to develop worthwhile affective characteristics with the average Mean of 3.50. Figure 4 clearly illustrates this.

\section{Discussion of Findings}

Research question one was designed to find out the underlying cultural indices of quality assurance needed by the operators of the university system. Perception of respondents as shown in table 1 in Rank Order indicated some of the cultural indices of quality assurance needed by the personnel of the University in ascending order. Research evidence clearly indicated that there are certain behaviour, character, values and beliefs that are required of administrators for quality assurance to achieve its goal of enhancing standards in the university system and the realization of national transformation as shown in the table analysis.

The cultural elements shown in table 1 agrees with Drucker and cited by Carnegie (1987) where he observed that effective management of modern organizations have shifted emphasis from what used to be the norm, where importance had been on laid down processes of the classical era in business management to the character, behaviour, values and beliefs of managers as expressed in their motivation drive, evidence of self-mastery and social skills. He further remarked that modern organizations cannot be an organization of boss and subordinates as it used to be, and that work processes must be organized as teams. Sashkin and Kiser (1993) equally gave credence to this fact. The duo reported that for quality assurance to develop in any organization, it will depend on the values and beliefs of some integrated elements of organizational culture. However, that most managers and other personnel do not possess these cultural traits and so, relate very poorly with their peers and subordinates. This observation equally applies to what the respondents perceived about the operators of the university system; that they lack most of the underlying cultural indices of quality assurance. Possessing excellent inter human relationship skills accordingly, is a crucial cultural elements for quality assurance to take root in any organization.

The reason for this finding is simply because change is a constant phenomenon in human life. The society, management of organizations and every thing are therefore susceptible to be dynamic nature of life, to the extent that what used to be may change in course of time as a result of new discoveries from science and research. The underlying reason for the change is usually for improvement and advancement in human activities.

The second research question sought to find out whether the cultural indices of quality assurance are being utilized to achieve the goals of university education by the operators of the system. Findings from the analysis revealed poor application of the cultural values by university personnel. This finding agrees with Agih \& Jonah-Eteli (2011).

The reason for this finding is a common knowledge. Since these human traits are lacking as observed by the respondents, the tendency is that they will equally be poorly utilized. Similarly, the poor usage of the cultural indices by the operators of the system could be attributed to the poor inculcation of these values to the young ones while still in school as mentioned earlier. This is equally compounded with the inappropriate manner the education system assesses the affective characteristics of learners. Yet at graduation, students are usually deemed to have been found worthy in character and learning.

Consequently, the poor results as shown in the table 2 could be responsible for the pitiable manner efforts at developing sustainable quality assurance framework in the institution have had. The poor development of these human traits has no doubt exacerbated corruption and other anti-social vices in the society. 
It is the importance of these human characteristics to the development of social organizations that every institution has ethics and other operational guidelines to direct the conduct of workers. These rules as equally found in the Nigerian universities are meant to direct and guide the behaviour of staff members to be of good conduct and to be productive, which are crucial for the realization of organizational goals.

Some of the age old characteristics of the affective domain of humans as earlier mentioned are discipline, cooperation, interest, responsibility, conscientiousness, patience, self-control and others. Accordingly, succeeding nations, organizations and individuals are those that possess and utilize the virtues enumerated which are the underlying cultural indices of quality assurance. For the education sub-sector, and the nation at large, this explains why efforts at improving standards and quality have not gained sufficient root over the years since most operators in the system do not utilize these virtues in administration.

Nigeria is more than fifty years old but she is still grappling with the problem of providing certain basic amenities like pipe-borne water, inter/ intra road network, steady power supply, primary health care and a host of others for her citizens. This is simply because some of the leaders have not imbibed and utilized the fundamental quality assurance culture that is crucial for national transformation in governance. In the recent Dana air crash that occurred on the fateful day of June 3, 2012 in Lagos which killed over 170 passengers, crew and residents, the imperative of applying quality assurance culture in organizational life came to the fore. Some public commentators have observed that the disaster could have been averted if officials of the company and those of the regulatory agencies in the air line business had exhibited some of the enduring qualities mentioned and other quality assurance ethics in performing their duties.

Furthermore, Yew (2000) and cited by Agih and Jonah-Eteli (2011), demonstrated the example of Singapore (a third word country in 1965, but now in the rank of the first) in his words that," I wrote this book for younger generation of Singaporeans who took stability, growth, and prosperity for granted. I wanted them to know how difficult it was for a small country of $640 \mathrm{sq} . \mathrm{km}$ with no natural resources to survive in the midst of larger, newly independent nations all pursuing nationalistic policies." In Lee Kuan Yew's estimation, what did the trick for them was superior intelligence, discipline, cooperation, honesty, respect for one another and for constituted authority, loyalty to ones country, the spirit of patriotism, dedication, developing the right attitude for the environment, and not natural resources since they were not endowed with such by nature. What did the magic for Singapore as documented and shown by research evidence are knowledge of the cultural indices of quality assurance and utilization of same in organizational and national life.

The last question sought for ways or means to be adopted to improve the usage of the cultural indices of quality assurance. The opinion of respondents ranged from proper development of the affective domain of pupils/ students before industry or work life, proper teachings in Churches and other religious groups to use of seminars/ workshops.

The all inclusive role of major socializing agents of society is important and it affirms the opinion of Peale (1938), where he observed that issues of the heart border on morality and character, and that the world is somehow built on sound moral foundations. In the same vein, Iheoma (1995) also remarked that:

\begin{abstract}
...what matters most to a nation's well being is its spiritual and moral health. Everything else which a nation strives for depends on this - whether it is national integration, political stability, economic development, or educational, scientific and technological progress. Nigeria is a country that is morally and spiritually sick. A basic aim of moral education in Nigerian schools must be to restore sanity to the nation's way of life through, discipline, respect and concern for others, justice and devotion to duty.
\end{abstract}

The foregoing illustrates the importance of developing enviable cultural virtues early enough in the life of the young ones who are in training to be the leaders of the country in the future. These virtues enhance the sustainability of quality assurance values and beliefs in individuals and organizational lives.

\title{
7. Conclusion/ Recommendations
}

The desire to improve and continuously pursue excellence in the educational service delivery in Nigeria has made quality assurance almost a household name by planners and managers of the system. This explains why most conferences and seminars in recent times in education have focused on quality assurance issues. Quality assurance, which has its root from the industrial sector, is concerned with quality improvement principles that work in systems' related fashion to evolve a philosophy of excellence in management. Usually, the principles are implemented in a holistic manner to bring about a new way of thinking and doing things right. In education, quality assurance has to do with setting standards for the various processes and activities that lead to the production of quality graduates by the training institutions. Interestingly, most of the efforts for the quality assurance drive in the education system have been focused on the "why" 
of the concept, which deals with customers' satisfaction. Emphasis on the "how" of the concept, which is concerned with the operators (the people), their values, ideals, which may be referred to as the cultural (virtues) aspects of quality assurance has not matched with what is being done for the processes of the system.

The study illustrated that some of the indices of motivation, self-mastery and social skills are cultural dimensions of quality assurance. They represent the "how" of the concept, which deals with the character and attitudinal dispositions of the operators of the university system for continuous quality improvement. Based on the conclusion, it was therefore recommended that the education system should inculcate in learners worthwhile affective traits; that proper assessment of the affective domain should be done, and such be considered also at promotion during terminal examinations for all the levels of education in Nigeria; university management staff should be patriotic, honest, disciplined and display a sense of responsibility at work. It has been noted that even if government is able to provide all the funds required to transform the university system, and where the operators are not sincere, such funds will be embezzled through corrupt practices. Furthermore, it is also recommended that managers of the system should show enthusiasm at work and display enviable faith and hope in the transformation of the university system back to her lost glory.

\section{References}

Academic Planning Unit. (2011). Niger Delta University, Wilberforce Island, Bayelsa State.

Agih, A. A. \& Jonah-Eteli, W. A.(2011). Effective Use of Continuous Assessment in Schools: Imperative for Moral Uprightness in Youths for Sustainable Development. Review of Education- Institute of Education Journal. University of Nigeria, Nsukka. 22 (1) 42-53.

Combs, P. H. (1985). The World Crises in Education: The View from the Eighties. New York: Oxford University Press.

Carnegie, D. (1987). The Leader in You. Boston: Harper Books

Enaohwo, J. O. (2008). Access, Cost and Quality in Nigerian Education-A Keynote address. In Nworgu, B. G \& Eke, E. I. Proceedings of the 23rd Annual Congress of the Nigerian Academy of Education. University of Nigeria, Nsukka.

Miller, K. (2002). Quality Assurance in Higher Education in the Commonwealth Caribbean. Paper presented at Seminar on Higher Education, Science and Technology in Latin-America and the Caribbean Responding to Expansion and Diversification. Fortile/a, Bra/11 March 8, 2002.

Peale, N.V. (1938). You Can Win. New York: Abingdon- Cokesbury Press.

Sashkin, M. \& Kiser, K. (1993). Putting Total Quality Management to Work. San Francisco: Berret-Koehier Publishers, Inc.

Whitely, P. (2001). Quality Assurance: Its Centrality to the Administration of Caribbean Tertiary Level Institutions. The Caribbean Education Annual. (1) 13-24.

Yew, K. L. (2000). From Third World to First- The Singapore Story: 1965-2000. New York: Harper Collins Publishers. 